\section{(6) OPEN ACCESS}

\title{
Wanna know about vaping? Patterns of message exposure, seeking and sharing information about e-cigarettes across media platforms
}

\author{
Sherry L Emery, ${ }^{1}$ Lisa Vera, ${ }^{2}$ Jidong Huang, ${ }^{1}$ Glen Szczypka ${ }^{1}$
}

\begin{abstract}
- Additional material is published online only. To view this file please visit the journal online (http://dx.doi.org/10. 1136/tobaccocontrol-2014051648)
\end{abstract}

${ }^{1}$ Health Media Collaboratory, Institute for Health Research and Policy, University of Illinois at Chicago, Chicago, Illinois, USA

${ }^{2}$ Moores Cancer Center, University of California San Diego, La Jolla, California, USA

\section{Correspondence to}

Dr Sherry L Emery, Health

Media Collaboratory, Institute

for Health Research and Policy, University of Illinois at Chicago, 1747 West Roosevelt Rd, Chicago, IL 60608, USA: slemery@uic.edu

Received 3 March 2014 Accepted 1 May 2014
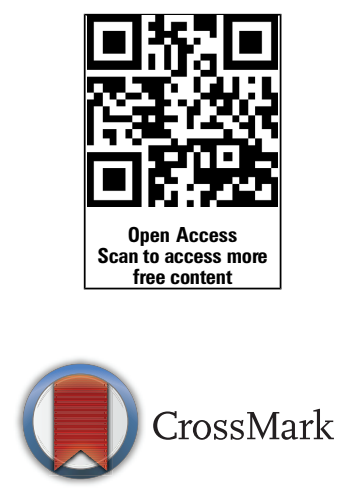

To cite: Emery SL, Vera L, Huang J, et al. Tob Control 2014;23:iii17-iii25.

\begin{abstract}
Background Awareness and use of electronic cigarettes has rapidly grown in the USA recently, in step with increased product marketing. Using responses to a population survey of US adults, we analysed demographic patterns of exposure to, searching for and sharing of e-cigarette-related information across media platforms.
\end{abstract}

Methods An online survey of 17522 US adults was conducted in 2013. The nationally representative sample was drawn from GfK Group's KnowledgePanel plus off-panel recruitment. Fixed effects logit models were applied to analyse relationships between exposure to, searching for and sharing of e-cigarette-related information and demographic characteristics, e-cigarette and tobacco use, and media behaviours.

Results High levels of awareness about e-cigarettes were indicated (86\% aware; $47 \%$ heard through media channels). Exposure to e-cigarette-related information was associated with tobacco use, age, gender, more education, social media use and time spent online. Although relatively small proportions of the sample had searched for $(\sim 5 \%)$ or shared ( 2\%) e-cigarette information, our analyses indicated demographic patterns to those behaviours. Gender, high income and using social media were associated with searching for e-cigarette information; lesbian, gay and bisexual and less education were associated with sharing. Current tobacco use, age, being Hispanic and time spent online were associated with both searching and sharing.

Conclusions US adults are widely exposed to e-cigarette marketing through the media; such marketing may differentially target specific demographic groups. Further research should longitudinally examine how exposure to, searching for and sharing of e-cigarette information relate to subsequent use of e-cigarettes and/or combustible tobacco.

\section{BACKGROUND}

Electronic nicotine delivery devices (ENDS) are battery-powered electronic devices that deliver nicotine in the form of heated vapour. ENDS encompass a variety of products with different shapes and sizes: while many small-sized ENDS look and feel like regular cigarettes, there are also medium-sized penstyle ENDS, popularly referred as 'e-hookahs' or 'vape pens', and large tank-size ENDS known as 'advanced personal vaporisers (APVs)', or 'Mods'. ENDS first appeared in China in 2004 and were introduced into the US market in 2007. ${ }^{1}$

Commonly called 'e-cigarettes', ENDS have rapidly emerged into public consciousness.
E-cigarette marketing appears across various media channels, notably including television and billboards-on which tobacco advertising has been prohibited since 1971 and 1998, respectively. While less than 5 years ago these products were scarcely known among the US populace, ${ }^{2-4}$ today television and radio ads for e-cigarettes feature catchy slogans and endorsements by celebrities and local radio personalities across the USA. ${ }^{5}$ Cab-top and bus displays, sports sponsorships, contests and giveaways-all illegal or highly regulated media platforms for cigarette promotion-supplement e-cigarettes' substantial presence in print and online. $^{67}$

There is evidence that rates of e-cigarette use and awareness also are increasing rapidly. In 2010, two surveys of American adults found overall that $40.2 \%$ of respondents had heard of e-cigarettes and that $11.4 \%$ of smokers, $2 \%$ of former smokers and $0.8 \%$ of never smokers had tried the products. $^{8}$ In $2010-2011,73 \%$ of US adult respondents $(\mathrm{N}=1520)$ to the International Tobacco Control Four-Country Study reported they had heard of e-cigarettes, $14.9 \%$ had tried e-cigarettes and $6 \%$ were current users. ${ }^{9}$ In 2013 , the CDC reported National Youth Tobacco Survey data indicating that experimentation and use of e-cigarettes doubled among middle and high school students from 2011 to 2012. As of 2012, this increase represented an estimated 1.78 million students who have used the products. ${ }^{10}$ In the largest study yet to examine e-cigarette use in the USA, our research team conducted an online survey with a nationally representative sample of American adults in which $86 \%$ of respondents reported being aware of e-cigarettes and $15 \%$ said they had tried them. ${ }^{11}$ Our results also indicated variance in e-cigarette use based on demographics; higher rates of use were reported among whites, young adults, those at higher income levels and/or members of the lesbian, gay and bisexual (LGB) communities. The differential appeal of e-cigarettes indicated by these use patterns suggests that product marketing may specifically target certain demographic groups. Yet little is known about how different groups encounter and interact with information about e-cigarettes. Research is needed to inform the public health community about the media platforms across which e-cigarette information is consumed.

This paper describes patterns of exposure to, searching for and sharing of information about e-cigarettes among a nationally representative sample of US adults. 


\section{METHODS}

\section{Data}

Data used in this study were collected via an online survey designed by the Health Media Collaboratory at the University of Illinois, Chicago, and fielded by The GfK Group (GfK) in February-March 2013 with 17522 US adults aged $\geq 18$, assessing media consumption, tobacco use status and exposure to tobacco-related messages.

Sampling frame: A nationally representative sample was drawn from GfK's KnowledgePanel, a probability-based panel that includes approximately 55000 adults recruited using random digit dialling supplemented by address-based sampling. ${ }^{12}$ KnowledgePanel members come from listed and unlisted telephone numbers; telephone, non-telephone and cell-phone-only households; and households with and without internet access, creating a representative sample. Of the 34097 KnowledgePanel members sampled, $61 \%$ completed the screening and $97 \%$ of those eligible completed the online survey. In addition to KnowledgePanel participants, GfK recruited an offpanel convenience sample that was included to achieve representation at the Designated Market Area level and to oversample for tobacco users. The convenience sample was recruited by screening people who clicked on online ads and quota-matching them to the probability sample based on demographics and tobacco use status. GfK screened names and addresses and removed duplicates before inviting participants to respond to the survey. Non-responders received up to four reminders; all respondents provided online consent. Response rate data for the convenience sample are unavailable because there is no known sampling frame.

Sample weighting: GfK applies statistical weighting adjustments to survey data for the purpose of offsetting any known deviations from probability sampling during sample selection.

\section{Measures}

Seen/heard e-cigarette-related information: The survey asked all respondents whether they have ever seen/heard information about e-cigarettes on television, on the radio, in the print media or online. We rely on this question to capture extent of passive exposure to e-cigarette-related information across media platforms. A dichotomous variable was constructed to indicate any positive response across platforms.

Searched for e-cigarette-related information: The survey asked respondents whether they have ever searched for information about e-cigarettes online or via other channels. We created a dichotomous variable to indicate any reported searching for e-cigarette information.

Shared e-cigarette-related information: The survey asked whether respondents have ever shared information about e-cigarettes across channels. A dichotomous variable indicates any reported information sharing.

Shared conditional on exposure or search: Individuals who have never seen/heard or searched for e-cigarette-related information are unlikely to share such information. Therefore, we analysed sharing e-cigarette information among the restricted sample of those reporting exposure to and/or searching for such information.

Explanatory variables-socioeconomic and demographic measures, tobacco use status, e-cigarette use, media access and use: We investigated individual-level characteristics likely to affect e-cigarette-related information exposure, searching and sharing, including socioeconomic and demographic variables associated with cigarette use, ${ }^{13}$ other tobacco use and access to and use of digital media and social networking platforms.
Socioeconomic status was measured by self-reported income and highest completed education level. We measured age, race, gender and sexual orientation (self-reported status as LGB). We constructed a dichotomous indicator that captures any other tobacco use in the 30 days prior to the survey, including smoking cigarettes, cigars, little cigars, cigarillos, pipe tobacco, hookah or using smokeless or dissolvable tobacco products. E-cigarette use in the 30 days prior to the survey was captured by a dichotomous indicator. Survey questions used to construct e-cigarette measures are presented in online supplementary table S4. Two variables measured media consumption: average number of hours spent online per day and whether respondent uses a social networking site. A complete list of variables and explanation of variable construction are presented in table 1 .

\section{Empirical models}

We specified fixed effects logit models to examine relationships between our explanatory variables and each of our five outcomes related to e-cigarette media consumption: exposure, search, share, share conditional on exposure and share conditional on search. Because media exposure and consumption vary across media markets and tobacco control policies vary across states, for each outcome we estimated two sets of fixed effects models: one for state-level fixed effects (table 2) and the other for media market fixed effects (see online supplementary table S1).

The fixed effects models were specified as follows:

$\mathrm{E}$ - cig Information media consumption

$=\beta_{0}+\beta_{1}$ Tobacco Use $+\beta_{2}$ Age $+\beta_{3}$ Gender

$+\beta_{4}$ Race $/$ Ethnicity $+\beta_{5}$ Education $+\beta_{6}$ Income

$+\beta_{7}$ LGB $+\beta_{8}$ Hours Online $+\beta_{9}$ Using Social Networking Sites

$+\beta_{10}$ State or Media Market Dummies + error

State fixed effects account for unmeasured state-specific characteristics that could be related to e-cigarette information consumption patterns and are relatively constant over time but vary by state. Similarly, media market fixed effects account for media market characteristics that are constant over time but could vary across media markets. We used tobacco use status in equation 1 because e-cigarette information may appeal not only to e-cigarette users but also to a broad group of consumers who use other tobacco products but do not currently use e-cigarettes. However, we did conduct analysis looking at e-cigarette use status, presented in online supplementary tables S2 and S3.

To investigate associations between e-cigarette use status and e-cigarette information consumption via different media channels, we estimate the following equation:

$$
\begin{aligned}
\text { E }- \text { cig Use }= & \beta_{0}+\beta_{1} \text { Media Platforms }+\beta_{2} \text { Age }+\beta_{3} \text { Gender } \\
& +\beta_{4} \text { Race } / \text { Ethnicity }+\beta_{5} \text { Education }+\beta_{6} \text { Income } \\
& +\beta_{7} \text { LGB }+\beta_{8} \text { Hours Online } \\
& +\beta_{9} \text { Using Social Networking Sites }+ \text { error }
\end{aligned}
$$

Estimates from equation 2 are presented in table 4, calculated separately for e-cigarette information exposure, search and sharing.

\section{RESULTS}

Table 1 presents detailed descriptive statistics for the variables used in the analyses. Close to half (47\%) of sample respondents 
Table 1 Descriptive statistics

\begin{tabular}{|c|c|c|c|}
\hline & Number of observations & Per cent/mean & $95 \% \mathrm{Cl})(\%)$ \\
\hline \multicolumn{4}{|l|}{ Dependent variables } \\
\hline Seen/heard information about e-cigarettes & 17452 & 47.70 & 46.5 to 48.9 \\
\hline Searched for information about e-cigarettes & 17452 & 4.90 & 4.5 to 5.4 \\
\hline Shared information about e-cigarettes & 17452 & 2.00 & 1.7 to 2.3 \\
\hline Shared information conditional on seen/heard & 8835 & 2.00 & 1.6 to 2.4 \\
\hline Shared information conditional on searched & 1449 & 16.00 & 12.8 to 19.1 \\
\hline \multicolumn{4}{|l|}{ E-cigarette prevalence } \\
\hline E-cigarettes awareness & 17480 & 86.40 & 85.6 to 87.3 \\
\hline Ever used e-cigarettes & 17477 & 14.80 & 14.0 to 15.5 \\
\hline Current use e-cigarettes & 17477 & 5.10 & 4.7 to 5.5 \\
\hline \multicolumn{4}{|l|}{ Explanatory variables } \\
\hline Tobacco user indicator & 17522 & 25.10 & 24.2 to 25.9 \\
\hline \multicolumn{4}{|l|}{ Age category } \\
\hline 18-24: 1, yes; 0, no (reference) & 17522 & 9.70 & 8.9 to 10.5 \\
\hline 25-44: 1 , yes; 0 , no & 17522 & 34.40 & 33.3 to 35.6 \\
\hline 45-64: 1 , yes; 0 , no & 17522 & 38.30 & 37.2 to 39.4 \\
\hline $65+: 1$, yes; 0 , no & 17522 & 17.50 & 16.7 to 18.4 \\
\hline Gender: 0 , male; 1 , female & 17522 & 52.00 & 50.8 to 53.2 \\
\hline \multicolumn{4}{|l|}{ Race/ethnicity } \\
\hline Non-Hispanic white: 1 , yes; 0 , no (reference) & 17522 & 68.10 & 66.9 to 69.3 \\
\hline Non-Hispanic black: 1 , yes; 0 , no & 17522 & 11.50 & 10.7 to 12.4 \\
\hline Hispanic: 1 , yes; 0 , no & 17522 & 13.50 & 12.5 to 14.4 \\
\hline Other: 1 , yes; 0 , no & 17522 & 6.90 & 6.2 to 7.5 \\
\hline \multicolumn{4}{|l|}{ Education } \\
\hline Less than high school graduate: 1 , yes; 0 , no (reference) & 17522 & 6.80 & 6.1 to 7.5 \\
\hline High school graduate: 1 , yes; 0, no & 17522 & 36.10 & 35.0 to 37.3 \\
\hline Some college: 1 , yes; 0 , no & 17522 & 31.20 & 30.1 to 32.2 \\
\hline College: 1 , yes; 0 , no & 17522 & 15.70 & 15.0 to 16.5 \\
\hline Any postcollege: 1 , yes; 0 , no & 17522 & 10.20 & 9.6 to 10.9 \\
\hline \multicolumn{4}{|l|}{ Household income } \\
\hline$<20 \mathrm{~K}: 1$, yes; 0 , no (reference) & 17522 & 14.20 & 13.3 to 15.0 \\
\hline 20-34.9K: 1 , yes; 0 , no & 17522 & 14.90 & 14.1 to 15.8 \\
\hline 35-49.9K: 1 , yes; 0 , no & 17522 & 13.30 & 12.5 to 14.0 \\
\hline 50-74.9K: 1 , yes; 0 , no & 17522 & 19.60 & 18.7 to 20.6 \\
\hline 75-124.9K: 1 , yes; 0 , no & 17522 & 27.40 & 26.4 to 28.5 \\
\hline $125 \mathrm{~K}+: 1$, yes; 0, no & 17522 & 10.60 & 9.9 to 11.3 \\
\hline LGB category: 0 , heterosexual or straight; 1 , lesbian, gay, bisexual & 17281 & 4.90 & 4.4 to 5.4 \\
\hline Use social networking sites: 1 , yes; 0 , no & 17474 & 87.40 & 86.7 to 88.2 \\
\hline Average daily hours spent on internet & 17024 & 3.05 & 3.00 to 3.10 \\
\hline
\end{tabular}

reported having ever seen/heard information about e-cigarettes on television, on the radio, in the print media or online. Approximately 5\% had ever searched for information about e-cigarettes online or via other channels. About $2 \%$ had ever shared information about e-cigarettes online, on social media or via other channels. Among those exposed to e-cigarette information, 2\% reported sharing such information. However, among those who have searched for e-cigarette information, $16 \%$ had shared such information.

Overall characteristics of respondents in our sample are comparable to other nationally representative population surveys.

\section{Seen/heard e-cigarette-related information}

Table 2 presents the results from the state fixed effects models. Online supplementary table S1 presents the results from the media market fixed effects models. The results of both sets of analyses were highly consistent. Thus, we focus below only on the findings from the state fixed effects models.

Tobacco users were almost twice as likely as non-users to have seen/heard information about e-cigarettes (OR 1.9). Adults age 65 and above were less likely than younger adults to have seen/ heard information about e-cigarettes (OR 0.8). Women were significantly less likely than men to be exposed to e-cigarette information (OR 0.8). Compared with non-Hispanic whites, non-white respondents were less likely to have been exposed to e-cigarette information. Higher educational attainment was positively associated with exposure to e-cigarette information. There were no differences in exposure across income categories. Neither LGB status nor social network use predicted exposure; however, each additional hour per day spent online increased the odds of exposure to information about e-cigarettes by $2 \%$ (OR 1.02). 
Table 2 Logistic regression with state fixed effects

\begin{tabular}{|c|c|c|c|c|c|c|c|c|c|c|}
\hline & \multicolumn{10}{|c|}{ E-cigarette-related information? } \\
\hline & \multicolumn{2}{|l|}{ Seen/heard } & \multicolumn{2}{|l|}{ Searched for } & \multicolumn{2}{|l|}{ Shared } & \multicolumn{2}{|c|}{$\begin{array}{l}\text { Shared conditional on seen/ } \\
\text { heard }\end{array}$} & \multicolumn{2}{|c|}{ Shared conditional on searched } \\
\hline & OR $(95 \% \mathrm{Cl})$ & $p$ Value & OR $(95 \% \mathrm{Cl})$ & p Value & OR $(95 \% \mathrm{Cl})$ & $\mathrm{p}$ Value & OR $(95 \% \mathrm{Cl})$ & $\mathrm{p}$ Value & OR $(95 \% \mathrm{Cl})$ & $\mathrm{p}$ Value \\
\hline \multicolumn{11}{|l|}{ Tobacco user } \\
\hline No & 1 & & 1 & & 1 & & 1 & & 1 & \\
\hline Yes & $1.90(1.70$ to 2.11$)$ & $<0.0001$ & 8.37 (6.39 to 10.96$)$ & $<0.0001$ & 5.23 (3.57 to 7.68$)$ & $<.0001$ & 5.24 (2.90 to 9.48$)$ & $<0.0001$ & $0.94(0.50$ to 1.75$)$ & 0.8376 \\
\hline \multicolumn{11}{|l|}{ Age } \\
\hline $18-24$ & 1 & & 1 & & 1 & & 1 & & 1 & \\
\hline $25-44$ & $0.97(0.79$ to 1.20$)$ & 0.7940 & $0.71(0.50$ to 1.01$)$ & 0.0585 & 0.51 (0.33 to 0.81$)$ & 0.0039 & 0.37 (0.21 to 0.68$)$ & 0.0011 & $0.97(0.45$ to 2.11$)$ & 0.9385 \\
\hline $45-64$ & $0.89(0.72$ to 1.09$)$ & 0.2534 & 0.64 (0.45 to 0.92$)$ & 0.0152 & $0.46(0.29$ to 0.71$)$ & 0.0006 & 0.48 (0.26 to 0.89$)$ & 0.0194 & $1.01(0.45$ to 2.24$)$ & 0.9827 \\
\hline $65+$ & $0.80(0.64$ to 1.00$)$ & 0.0506 & $0.40(0.25$ to 0.64$)$ & 0.0001 & 0.36 (0.19 to 0.69$)$ & 0.0022 & 0.18 (0.08 to 0.41$)$ & $<0.0001$ & $0.17(0.05$ to 0.54$)$ & 0.0027 \\
\hline \multicolumn{11}{|l|}{ Gender } \\
\hline Male & 1 & & 1 & & 1 & & 1 & & 1 & \\
\hline Female & $0.80(0.72$ to 0.88$)$ & $<0.0001$ & 1.27 (1.05 to 1.55$)$ & 0.0160 & $1.22(0.91$ to 1.63$)$ & 0.1874 & 1.33 (0.88 to 2.00$)$ & 0.1779 & 0.97 (0.62 to 1.53$)$ & 0.9010 \\
\hline \multicolumn{11}{|l|}{ Race } \\
\hline White & 1 & & 1 & & 1 & & 1 & & 1 & \\
\hline Black & 0.98 (0.83 to 1.17$)$ & 0.8584 & 0.80 (0.55 to 1.17$)$ & 0.2480 & 1.09 (0.67 to 1.79$)$ & 0.7317 & 0.50 (0.25 to 0.99$)$ & 0.0453 & 0.63 (0.28 to 1.44$)$ & 0.2742 \\
\hline Hispanic & $0.82(0.69$ to 0.99$)$ & 0.0363 & $0.72(0.49$ to 1.06$)$ & 0.0918 & 1.55 (1.01 to 2.38$)$ & 0.0440 & 0.93 (0.47 to 1.84 ) & 0.8350 & $0.54(0.22$ to 1.32$)$ & 0.1787 \\
\hline Other & 0.72 (0.58 to 0.90$)$ & 0.0039 & 1.28 (0.84 to 1.95$)$ & 0.2555 & 1.17 (0.61 to 2.23$)$ & 0.6341 & 0.94 (0.51 to 1.73 ) & 0.8414 & 0.44 (0.20 to 0.99$)$ & 0.0461 \\
\hline \multicolumn{11}{|l|}{ Education } \\
\hline$<$ High school & 1 & & 1 & & 1 & & 1 & & 1 & \\
\hline High school graduate & $1.22(0.96$ to 1.55$)$ & 0.1129 & 1.29 (0.77 to 2.16$)$ & 0.3345 & $0.39(0.22$ to 0.69$)$ & 0.0012 & 0.67 (0.20 to 2.29 ) & 0.5269 & 6.59 (1.03 to 42.20$)$ & 0.0467 \\
\hline Some college & 1.36 (1.07 to 1.73$)$ & 0.0119 & 1.75 (1.04 to 2.93$)$ & 0.0341 & $0.59(0.34$ to 1.00$)$ & 0.0519 & 1.02 (0.32 to 3.25$)$ & 0.9762 & 8.50 (1.35 to 53.59$)$ & 0.0227 \\
\hline Bachelor degree & 1.51 (1.17 to 1.96$)$ & 0.0017 & 1.46 (0.84 to 2.55$)$ & 0.1850 & $0.45(0.25$ to 0.81$)$ & 0.0071 & 0.87 (0.27 to 2.83 ) & 0.8226 & 6.78 (1.08 to 42.52$)$ & 0.0412 \\
\hline Any post college & 1.24 (0.94 to 1.63$)$ & 0.1287 & $1.70(0.88$ to 3.28$)$ & 0.1139 & 0.56 (0.29 to 1.08$)$ & 0.0851 & $1.14(0.32$ to 4.06$)$ & 0.8348 & 5.32 (0.73 to 38.82$)$ & 0.0990 \\
\hline \multicolumn{11}{|l|}{ Income } \\
\hline$<20 \mathrm{~K}$ & 1 & & 1 & & 1 & & 1 & & 1 & \\
\hline $20-34.9 \mathrm{~K}$ & $1.00(0.83$ to 1.20$)$ & 0.9791 & 1.22 (0.88 to 1.69$)$ & 0.2322 & $1.26(0.73$ to 2.19$)$ & 0.4063 & 1.69 (0.80 to 3.57$)$ & 0.1661 & $1.00(0.48$ to 2.09$)$ & 0.9945 \\
\hline $35-49.9 \mathrm{~K}$ & 1.06 (0.88 to 1.28$)$ & 0.5534 & 1.38 (0.98 to 1.95$)$ & 0.0647 & $0.86(0.51$ to 1.45$)$ & 0.5697 & 1.28 (0.62 to 2.65$)$ & 0.4972 & 1.01 (0.46 to 2.21$)$ & 0.9781 \\
\hline $50-74.9 \mathrm{~K}$ & $1.00(0.84$ to 1.20$)$ & 0.9889 & 1.73 (1.25 to 2.39$)$ & 0.0009 & $1.15(0.74$ to 1.80$)$ & 0.5336 & 1.50 (0.88 to 2.58 ) & 0.1404 & $1.20(0.61$ to 2.37$)$ & 0.5944 \\
\hline $75-124.9 \mathrm{~K}$ & 0.91 (0.76 to 1.08$)$ & 0.2731 & 1.46 (1.03 to 2.06$)$ & 0.0314 & 1.12 (0.66 to 1.91$)$ & 0.6701 & 2.25 (1.26 to 4.02$)$ & 0.0063 & 1.97 (0.92 to 4.22$)$ & 0.0795 \\
\hline $125 \mathrm{~K}+$ & 0.86 (0.69 to 1.08$)$ & 0.1922 & 0.89 (0.55 to 1.43$)$ & 0.6217 & 0.82 (0.40 to 1.67$)$ & 0.5904 & 1.29 (0.54 to 3.09$)$ & 0.5642 & 2.34 (0.83 to 6.63$)$ & 0.1096 \\
\hline \multicolumn{11}{|l|}{ LGB } \\
\hline No & 1 & & 1 & & 1 & & 1 & & 1 & \\
\hline Yes & $0.96(0.77$ to 1.20$)$ & 0.7236 & 1.39 (0.94 to 2.06$)$ & 0.1045 & 1.63 (1.01 to 2.65$)$ & 0.0463 & 2.29 (1.31 to 4.02$)$ & 0.0038 & 0.95 (0.49 to 1.81$)$ & 0.8669 \\
\hline \multicolumn{11}{|l|}{ Use social media } \\
\hline No & 1 & & 1 & & 1 & & 1 & & 1 & \\
\hline Yes & 1.33 (1.14 to 1.55$)$ & 0.0003 & 2.29 (1.48 to 3.54$)$ & 0.0002 & 1.37 (0.65 to 2.88 ) & 0.4121 & 1.69 (0.67 to 4.24$)$ & 0.2661 & 1.11 (0.25 to 4.88$)$ & 0.8936 \\
\hline Average daily hours on internet & $1.02(1.00$ to 1.04$)$ & 0.0321 & 1.05 (1.03 to 1.07$)$ & $<0.0001$ & 1.05 (1.02 to 1.08$)$ & 0.0021 & 1.08 (1.04 to 1.12$)$ & 0.0002 & $1.06(1.01$ to 1.11$)$ & 0.0117 \\
\hline Observations & 16796 & & 16796 & & 16796 & & 8568 & & 1409 & \\
\hline No. of yes & 8568 & & 1409 & & 494 & & 264 & & 226 & \\
\hline
\end{tabular}

LGB, lesbian, gay, and bisexual. 
Table 3 Media platforms for seeing/hearing, searching and sharing e-cigarette-related information

\begin{tabular}{|c|c|c|c|c|c|}
\hline & Overall (\%) & Among e-cig users (\%) & Among non-e-cig users (\%) & Un-adj OR (95\% Cl) & $\chi^{2} \mathrm{p}$ Value \\
\hline \multicolumn{6}{|l|}{ Seen/heard platforms $(n=5906)$} \\
\hline Regular television & $66.1(64.2-68.1)$ & $59.6(54.8-64.5)$ & $66.8(64.7-68.9)$ & 0.73 (0.59 to 0.92 ) & 0.0065 \\
\hline Radio & $19.2(17.6-20.8)$ & $25.9(21.3-30.5)$ & $18.5(16.8-20.3)$ & 1.53 (1.18 to 2.00$)$ & 0.0014 \\
\hline Banner ads on any other website & $14.1(12.7-15.6)$ & $14.5(11.3-17.8)$ & $14.0(12.5-15.6)$ & 1.04 (0.78 to 1.39$)$ & 0.7852 \\
\hline Email & $13.3(12.1-14.6)$ & $25.5(21.3-29.6)$ & $12.1(10.8-13.4)$ & 2.48 (1.93 to 3.18$)$ & $<0.0001$ \\
\hline Internet search engines & $11.1(9.9-12.3)$ & $26.9(22.4-31.3)$ & $9.5(8.3-10.7)$ & 3.50 (2.67 to 4.58 ) & $<0.0001$ \\
\hline Facebook & $8.6(7.6-9.7)$ & $22.2(18.3-26.1)$ & $7.3(6.3-8.3)$ & 3.64 (2.78 to 4.78$)$ & $<0.0001$ \\
\hline Online news sources & $8.1(7.0-9.2)$ & $10.2(7.7-12.6)$ & $7.9(6.8-9.1)$ & 1.31 (0.96 to 1.79 ) & 0.0886 \\
\hline YouTube (and other video sharing sites) & $3.8(3.0-4.5)$ & $10.8(8.3-13.4)$ & $3.1(2.3-3.8)$ & 3.86 (2.66 to 5.60$)$ & $<0.0001$ \\
\hline Television viewing websites like Hulu & $3.0(2.4-3.6)$ & $7.9(5.8-10.0)$ & $2.5(1.9-3.1)$ & 3.37 (2.28 to 4.97$)$ & $<0.0001$ \\
\hline Some other social network (specify) & $2.2(1.6-2.9)$ & $1.7(0.2-3.3)$ & $2.3(1.6-3.0)$ & 0.75 (0.29 to 1.94$)$ & 0.5524 \\
\hline Twitter & $1.2(0.9-1.5)$ & $7.7(5.5-9.9)$ & $0.5(0.3-0.7)$ & 16.97 (9.52 to 30.27 ) & $<0.0001$ \\
\hline Tumblr (and other blogging sites, like blogger) & $0.5(0.3-0.7)$ & $2.7(1.4-4.0)$ & $0.3(0.1-0.5)$ & 9.41 (4.41 to 20.07 ) & $<0.0001$ \\
\hline \multicolumn{6}{|l|}{ Searched platforms ( $n=799$ ) } \\
\hline Internet search engines & $79.9(75.2-84.7)$ & $75.6(69.2-82.0)$ & $84.8(77.9-91.8)$ & $0.55(0.29$ to 1.05$)$ & 0.0694 \\
\hline Facebook & $15.5(12.1-18.8)$ & $22.9(17.5-28.4)$ & $7.0(4.0-10.0)$ & 3.95 (2.26 to 6.91$)$ & $<0.0001$ \\
\hline Online news sources & $12.0(8.9-15.1)$ & $13.4(9.3-17.5)$ & $10.4(5.6-15.2)$ & 1.33 (0.72 to 2.48$)$ & 0.3617 \\
\hline YouTube (and other video sharing sites) & $11.4(7.9-14.8)$ & $15.8(11.4-20.2)$ & $6.4(0.7-12.0)$ & 2.76 (1.01 to 7.50$)$ & 0.0429 \\
\hline Twitter & $6.6(4.5-8.6)$ & $9.1(6.0-12.2)$ & $3.7(1.2-6.2)$ & 2.62 (1.17 to 5.84$)$ & 0.015 \\
\hline Tumblr (and other blogging sites, like blogger) & $5.8(3.2-8.4)$ & $8.5(3.9-13.0)$ & $2.9(1.0-4.7)$ & 3.14 (1.29 to 7.65$)$ & 0.0069 \\
\hline Some other social network (specify) & $1.8(0.8-2.7)$ & $1.4(0.2-2.5)$ & $2.2(0.6-3.8)$ & 0.61 (0.20 to 1.89 ) & 0.3897 \\
\hline \multicolumn{6}{|l|}{ Shared platforms $(n=363)$} \\
\hline Word of mouth & $53.9(45.2-62.6)$ & $54.4(45.1-63.7)$ & $53.6(38.9-68.2)$ & 1.03 (0.51 to 2.08$)$ & 0.9262 \\
\hline Facebook & $33.2(26.2-40.2)$ & $48.5(39.1-57.9)$ & $18.3(10.6-25.9)$ & 4.22 (2.23 to 7.98$)$ & $<0.0001$ \\
\hline Text message & $24.2(16.7-31.6)$ & $31.8(22.9-40.7)$ & $16.9(5.1-28.6)$ & 2.30 (0.90 to 5.86$)$ & 0.0769 \\
\hline Email & $22.4(16.1-28.8)$ & $26.8(18.6-35.0)$ & $18.3(8.9-27.7)$ & 1.63 (0.77 to 3.48$)$ & 0.1932 \\
\hline Twitter & $11.8(7.9-15.7)$ & $17.2(11.1-23.2)$ & $6.5(2.1-10.8)$ & 3.01 (1.30 to 6.97$)$ & 0.0059 \\
\hline YouTube (and other video sharing sites) & $10.9(6.6-15.3)$ & $14.0(8.5-19.6)$ & $7.9(1.3-14.6)$ & 1.90 (0.69 to 5.27 ) & 0.2076 \\
\hline Tumblr (and other blogging sites, like blogger) & $8.7(3.6-13.8)$ & $11.4(6.6-16.2)$ & $6.1(0.0-15.1)$ & $1.99(0.38$ to 10.44$)$ & 0.4132 \\
\hline Some other social network (specify) & $3.9(0.0-7.7)$ & $3.5(0.0-7.3)$ & $4.2(0.0-10.8)$ & $0.81(0.11$ to 5.93$)$ & 0.8378 \\
\hline
\end{tabular}

\section{Searched for e-cigarette-related information}

Being a current tobacco user significantly increased one's odds of searching for information about e-cigarettes (OR 8.4). There was a negative age gradient in searching for information about e-cigarettes, with young adults most likely to have searched; as age increases, the odds of searching for e-cigarette information significantly decrease. Female respondents were more likely to have searched for such information compared with men (OR 1.27). There was no significant association between race/ethnicity and the likelihood of searching for e-cigarette information. Respondents reporting some college were more likely to have searched for e-cigarette information compared with those without a high school diploma (OR 1.75). Respondents with household income of \$35000-\$50 000, \$50 000-\$75000 or $\$ 75000-\$ 125000$ were more likely to have searched for e-cigarette information than those with household incomes < $\$ 20000$ (ORs 1.38, 1.73 and 1.46, respectively). LGB respondents were not statistically different from their heterosexual counterparts in searching for e-cigarette information. Each additional hour spent online significantly increased the odds of having searched for e-cigarette information (OR 1.05); using a social network nearly doubled (OR 1.82) the likelihood of having searched for e-cigarette information.

\section{Shared e-cigarette-related information}

Tobacco users were five times as likely as non-users to report sharing information about e-cigarettes (OR 5.23). Young adults were nearly twice as likely as other respondents to have shared e-cigarette information. There were no significant differences in e-cigarette information sharing by gender or income. Latinos were more likely than non-Hispanic white respondents to report information sharing (OR 1.59). Those with the lowest educational attainment were significantly more likely than others to have shared e-cigarette information. LGB respondents were more likely than their hetero counterparts to have shared e-cigarette information (OR 1.63). Each additional hour online per day was associated with higher probability of sharing e-cigarette information (OR 1.05). Using social networks did not predict sharing e-cigarette information.

\section{Shared e-cigarette-related information conditional on exposure and search}

Among respondents reporting exposure to e-cigarette information, tobacco users were over five times as likely as non-users to share such information (OR 5.24), and young adults were more than twice as likely as others to report sharing. Gender and education were unrelated to sharing conditional on exposure. African-Americans who had been exposed to e-cigarette information were significantly less likely than whites to share that information. Conditional on exposure, LGB were more than twice as likely as heterosexual respondents to share e-cigarette information (OR 2.3). Time spent online was positively associated with sharing conditional on exposure (OR 1.08). 
Table 4 Association between current e-cigarette use status and media platforms

\begin{tabular}{|c|c|c|c|c|c|c|c|c|}
\hline & \multicolumn{3}{|l|}{ Exposure platforms } & \multicolumn{3}{|l|}{ Search platforms } & \multicolumn{2}{|l|}{ Sharing platforms } \\
\hline & OR $(95 \% \mathrm{Cl})$ & $\mathrm{p}$ Value & & OR $(95 \% \mathrm{Cl})$ & $\mathrm{p}$ Value & & OR $(95 \% \mathrm{Cl})$ & p Value \\
\hline Regular television & $0.90(0.70$ to 1.16$)$ & 0.4209 & & & & Word of mouth & 2.60 (1.03 to 6.58$)$ & 0.0432 \\
\hline Radio & 1.25 (0.92 to 1.70$)$ & 0.1612 & & & & Text message & 2.40 (0.87 to 6.65$)$ & 0.0922 \\
\hline TV viewing sites like Hulu & 1.69 (1.00 to 2.87$)$ & 0.0518 & & & & & & \\
\hline Twitter & 7.75 (3.41 to 17.61$)$ & $<0.0001$ & Twitter & 0.84 (0.31 to 2.29$)$ & 0.7347 & Twitter & $1.22(0.43$ to 3.47$)$ & 0.7140 \\
\hline Facebook & 1.73 (1.21 to 2.46$)$ & 0.0025 & Facebook & 3.35 (1.65 to 6.81$)$ & 0.0009 & Facebook & 4.68 (1.87 to 11.72$)$ & 0.0010 \\
\hline YouTube/video sharing sites & $1.14(0.69$ to 1.87$)$ & 0.6087 & YouTube/ video sharing sites & 1.96 (0.77 to 4.99$)$ & 0.1581 & YouTube/ video sharing sites) & 1.35 (0.51 to 3.57$)$ & 0.5443 \\
\hline Tumblr/blogging sites & $1.58(0.36$ to 6.87$)$ & 0.5404 & Tumblr/blogging sites & 2.01 (0.64 to 6.36$)$ & 0.2336 & Tumblr/blogging sites & $1.44(0.33$ to 6.39$)$ & 0.6297 \\
\hline Email & 1.53 (1.11 to 2.11$)$ & 0.0096 & & & & Email & $1.42(0.60$ to 3.37$)$ & 0.4217 \\
\hline Internet search engines & 2.79 (2.03 to 3.85$)$ & $<0.0001$ & Internet search engines & $0.93(0.45$ to 1.95$)$ & 0.8508 & & & \\
\hline Online news sources & 0.67 (0.44 to 1.04$)$ & 0.0716 & Online news sources & 1.31 (0.65 to 2.64$)$ & 0.4537 & & & \\
\hline Other social networks & $1.00(0.36$ to 2.79$)$ & 0.9936 & Other social networks & 0.59 (0.15 to 2.24$)$ & 0.4340 & Other social networks & $1.57(0.27$ to 9.19$)$ & 0.6185 \\
\hline Banner ads on any other website & $0.70(0.50$ to 0.99$)$ & 0.0425 & & & & & & \\
\hline Age & & & Age & & & Age & & \\
\hline $18-24$ & 1 & & $18-24$ & 1 & & $18-24$ & 1 & \\
\hline $25-44$ & 0.78 (0.53 to 1.14$)$ & 0.1998 & $25-44$ & 1.35 (0.65 to 2.78$)$ & 0.4183 & $25-44$ & $2.08(0.78$ to 5.60$)$ & 0.1455 \\
\hline $45-64$ & 0.75 (0.50 to 1.12$)$ & 0.1570 & $45-64$ & 0.95 (0.44 to 2.06$)$ & 0.8948 & $45-64$ & $1.13(0.37$ to 3.49$)$ & 0.8303 \\
\hline $65+$ & $0.45(0.25$ to 0.81$)$ & 0.0076 & $65+$ & $0.63(0.24$ to 1.67$)$ & 0.3508 & $65+$ & 0.23 (0.06 to 0.93$)$ & 0.0394 \\
\hline Gender & & & Gender & & & Gender & & \\
\hline Male & 1 & & Male & 1 & & Male & 1 & \\
\hline Female & 0.88 (0.69 to 1.14$)$ & 0.3295 & Female & 0.51 (0.31 to 0.81$)$ & 0.0049 & Female & $0.36(0.17$ to 0.78$)$ & 0.0098 \\
\hline Race & & & Race & & & Race & & \\
\hline White & 1 & & White & 1 & & White & 1 & \\
\hline Black & 0.55 (0.34 to 0.89$)$ & 0.0147 & Black & 0.49 (0.21 to 1.14$)$ & 0.0991 & Black & 0.46 (0.16 to 1.36$)$ & 0.1621 \\
\hline Hispanic & $0.82(0.55$ to 1.25$)$ & 0.3572 & Hispanic & 0.65 (0.26 to 1.63$)$ & 0.3578 & Hispanic & $0.69(0.24$ to 2.00$)$ & 0.4881 \\
\hline Other & $0.97(0.64$ to 1.49$)$ & 0.9046 & Other & 1.19 (0.51 to 2.81$)$ & 0.6876 & Other & $0.91(0.27$ to 3.10$)$ & 0.8831 \\
\hline Education & & & Education & & & Education & & \\
\hline$<$ High school & 1 & & $<$ High school & 1 & & $<$ High school & 1 & \\
\hline High school graduate & 1.11 (0.65 to 1.88$)$ & 0.7076 & High school graduate & $0.28(0.10$ to 0.81$)$ & 0.0195 & High school graduate & 0.52 (0.12 to 2.17$)$ & 0.3650 \\
\hline Some college & $1.11(0.66$ to 1.87$)$ & 0.6918 & Some college & 0.22 (0.08 to 0.63$)$ & 0.0047 & Some college & 1.02 (0.27 to 3.84$)$ & 0.9788 \\
\hline Bachelor degree & $0.68(0.38$ to 1.22$)$ & 0.1971 & Bachelor degree & $0.27(0.09$ to 0.80$)$ & 0.0180 & Bachelor degree & $0.53(0.13$ to 2.20$)$ & 0.3788 \\
\hline Any post college & $0.42(0.21$ to 0.83$)$ & 0.0121 & Any post college & $0.16(0.04$ to 0.67$)$ & 0.0117 & Any post college & $1.16(0.20$ to 6.82$)$ & 0.8731 \\
\hline Income & & & Income & & & Income & & \\
\hline$<20 \mathrm{~K}$ & 1 & & $<20 \mathrm{~K}$ & 1 & & $<20 \mathrm{~K}$ & 1 & \\
\hline $20-34.9 \mathrm{~K}$ & $1.40(0.92$ to 2.13$)$ & 0.1203 & 20 to $34.9 \mathrm{~K}$ & 1.55 (0.74 to 3.26$)$ & 0.2494 & $20-34.9 \mathrm{~K}$ & 1.19 (0.38 to 3.66$)$ & 0.7677 \\
\hline $35-49.9 \mathrm{~K}$ & $1.12(0.72$ to 1.75$)$ & 0.6163 & $35-49.9 \mathrm{~K}$ & 0.81 (0.38 to 1.76$)$ & 0.5990 & $35-49.9 \mathrm{~K}$ & $1.49(0.43$ to 5.10$)$ & 0.5278 \\
\hline $50-74.9 \mathrm{~K}$ & $1.15(0.76$ to 1.75$)$ & 0.5014 & $50-74.9 \mathrm{~K}$ & 1.26 (0.60 to 2.64$)$ & 0.5490 & $50-74.9 \mathrm{~K}$ & $0.71(0.23$ to 2.20$)$ & 0.5470 \\
\hline 75-124.9K & $0.96(0.63$ to 1.46$)$ & 0.8366 & $75-124.9 \mathrm{~K}$ & 1.58 (0.70 to 3.57$)$ & 0.2676 & $75-124.9 \mathrm{~K}$ & 0.79 (0.24 to 2.60$)$ & 0.7005 \\
\hline $125 \mathrm{~K}+$ & $1.23(0.68$ to 2.24$)$ & 0.4929 & $125 K+$ & $2.80(0.84$ to 9.30$)$ & 0.0928 & $125 K_{+}$ & 28.70 (2.86 to 288.30 ) & 0.0043 \\
\hline
\end{tabular}




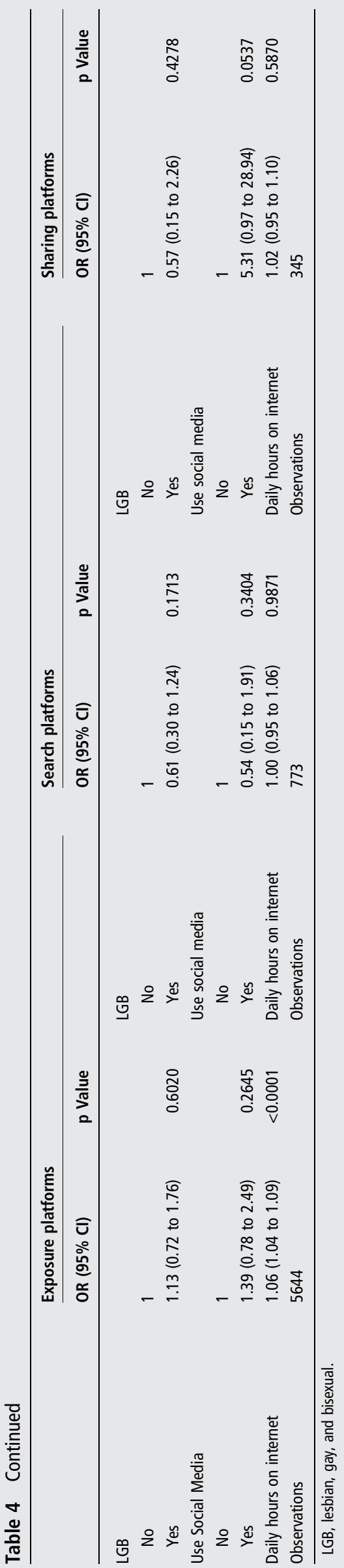

Conditional on having searched, tobacco use status, gender, income, LGB status and use of social media were unrelated to sharing e-cigarette information. Respondents aged $\geq 65$ and those in the other race/ethnicity category were significantly less likely to share e-cigarette information (ORs 0.17 and 0.44 , respectively). Among those who had searched for e-cigarette information, respondents who had completed high school or more were significantly more likely to have shared such information compared with those with no high school diploma. Each additional hour spent online increased the likelihood of sharing e-cigarette information, among respondents who had searched for that information.

\section{Media platforms involved in e-cigarette-related information exposure, searching and sharing}

Table 3 summarises the media platforms involved in e-cigarette-related information exposure, searching and sharing. Television is by far the most common channel on which people have encountered information about e-cigarettes, with $66 \%$ of those who have reported such exposure saying they saw it on TV. Radio (19\%), banner ads (14\%), email (13\%), internet search engines (11\%) and Facebook (9\%) were also relatively frequently reported as platforms where people encountered e-cigarette information. Not surprisingly, internet search engines were the prominent platform where people searched for e-cigarette information, accounting for $80 \%$ of respondents who had searched for e-cigarette information in the 30 days prior to the survey. Facebook (15\%), online news sources (12\%), YouTube (11\%) and Twitter (7\%) were also common platforms where people searched for e-cigarette information. Word of mouth was the largest channel for sharing e-cigarette information: $54 \%$ of those who had shared e-cigarette information in the 30 days prior to the survey had done so by word of mouth. Respondents also reported sharing e-cigarette information via Facebook (33\%), texting (24\%), email (22\%), Twitter (12\%), YouTube (11\%) and blogs (9\%).

Table 4 presents differences in using media platforms by e-cigarette use status. Compared with non-e-cigarette users who were exposed to e-cigarette information, e-cigarette users were more likely to be exposed to e-cigarette information via TV viewing sites (eg, Hulu), Twitter, Facebook, email and internet search engines. Compared with non-e-cigarette users who had searched for e-cigarette information, e-cigarette users were more likely to search for such information on Facebook. Compared with non-users who had shared e-cigarette information, e-cigarette users were more likely to share such information via word of mouth and Facebook.

\section{CONCLUSIONS AND DISCUSSION}

While a few studies have assessed overall awareness about e-cigarettes, ${ }^{8} 14$ this is the first to characterise levels of exposure to, searching for and sharing of e-cigarette-related information across media and other communications channels. The results of this research indicate high levels of awareness; $86 \%$ of the sample was aware of e-cigarettes and nearly half (47\%) had heard about them via media channels, significant findings given how recently these products have entered the market and the fact that less than $20 \%$ of the US population was aware of them 5 years ago. ${ }^{15}$ Passive exposure to e-cigarette messaging was more likely among tobacco users, young adults, males, those with education beyond high school and those who use social media and spend more time online.

Television represented the most common medium through which people reported being exposed to e-cigarette information. 
Our survey did not measure the source or valence of televised e-cigarette information; nonetheless, this finding may have implications for e-cigarette marketing regulation. While we cannot directly predict the effects of a television e-cigarette advertising ban, studies of combustible tobacco indicate that such bans are associated with reduced use of the products. ${ }^{16}$ Lessons learned from the Master Settlement Agreement suggest that e-cigarette manufacturers may simply circumvent a ban on televised ads by increasingly promoting their products through event sponsorship, social media and product websites. ${ }^{17} \mathrm{~A}$ recent congressional investigation demonstrated that such e-cigarette promotions already are being used to target US youth. ${ }^{18}$ Our finding that e-cigarette users are more likely to be exposed to e-cigarette information through channels prone to individually targeted marketing, such as TV viewing sites, Twitter, Facebook, YouTube, email and internet search engines, also suggest targeted marketing towards e-cigarette users via non-traditional media channels.

Although a relatively small proportion of our sample reported having searched for $(\sim 5 \%)$ or shared $(\sim 2 \%)$ e-cigarette-related information across various communications channels, e-cigarettes are a relatively new phenomenon, and product marketing has increased dramatically since this survey was fielded. ${ }^{19}$ To add perspective to these findings, Fox and Duggan ${ }^{20}$ reported in 2013 that, in the past 12 months, $16 \%$ of internet users had searched for others sharing a health concern, and $8 \%$ had posted a health-related question or shared personal health experiencesbehaviours likely more expected from the general population than searching for or sharing e-cigarette information.

While a few studies have confirmed potential exposure to internet information related to e-cigarettes, ${ }^{21} 22$ this is the first paper to examine search for and sharing of e-cigarette information online. Our results uncovered important demographic differences in searching and sharing behaviour. Current tobacco use was positively and significantly associated with likelihood of searching for e-cigarette information, not surprising given that the products may be perceived as smoking cessation aids. Also not surprising are our findings that e-cigarette users were more likely than non-users to search for e-cigarette information on Facebook, and more likely than non-users to share such information via word of mouth and Facebook. Whereas age had an apparent inverse relationship with search activity, it was difficult to separate differences explained by age from those explained by education level without further interaction analyses. Our results indicating that Latinos and self-identified LGB were more likely than other demographic groups to share e-cigarette information, even after controlling for income, time spent online and use of social media, warrant further research to uncover the mechanisms behind higher levels of e-cigarette information sharing among these populations.

Not surprisingly, more time spent using the internet and presence on social media networks increased one's likelihood of searching for and sharing e-cigarette information. Perhaps once people reach a certain threshold of passive exposure to information about a product, perception of its popularity prompts them to begin actively searching for and sharing information about the product. Although this question cannot be answered using the cross-sectional analysis reported here, the Wave 2 follow-up survey will provide opportunity to test the theory using longitudinal data.

Marketing and promotion of e-cigarettes, not only via traditional media channels but also online ${ }^{1}$ and across social media, ${ }^{19}$ has likely contributed significantly to the rapid rise in awareness and popularity of the products. Our work recently identified exponential growth in e-cigarette promotional spending over the past 3 years, with expenditures for the first two quarters of 2013 already double the amount spent during all of 2012. ${ }^{23}$ The current analysis represents an important step towards understanding how e-cigarette-related information may reach various audiences and audience characteristics that make such information more likely to be shared. In addition to product marketing efforts to target specific demographics, inherent product qualities may make e-cigarettes more appealing to certain groups (ie, technological novelty). Some demographic groups may be more enthusiastic adopters of new technology and more likely to spread product information to their social networks. Further research should examine product characteristics associated with higher rates of uptake among specific groups.

This study is limited first by its cross-sectional design, which does not allow characterisation of trends or behaviour changes over time. Second, the data represent self-report with no objective validation measures. Third, this study did not assess the content of e-cigarette information searched for or shared by respondents; content analysis may be an important component of future studies. Fourth, our findings indicate low prevalence of searching and sharing e-cigarette information; however, the expected frequency of searching for or sharing any given topic on a specific day is likely to be low.

The findings from our study have implications for regulatory and public health policy surrounding e-cigarettes. Clearly, US adults are being exposed to e-cigarette marketing on the internet and in social media networks. Current tobacco users are more likely to search for e-cigarette-related information, suggesting that they may perceive the products as viable cessation aids, a practical alternative to combustible cigarettes in settings where smoking is banned or a way to mitigate the harm of ongoing tobacco use. Exposure to, searching for and sharing of e-cigarette information differs by demographics, possibly indicating that marketing differentially targets specific population groups. Further research should explore how subpopulations encounter and share information about e-cigarettes and how those behaviours relate to subsequent use of either e-cigarettes or combustible tobacco. Examining the inter-relationships between exposure to, searching for and sharing e-cigarette information using longitudinal data may illuminate where the communication cycle begins and whether that cycle is different for e-cigarettes than for regular cigarettes.

\section{What the paper adds}

- This is the first study to characterise levels of exposure to, searching for and sharing of e-cigarette-related information across media and other communications channels.

- This study reveals important demographic differences in exposure to, searching for and exchange of information related to e-cigarettes. These findings have implications for regulatory and public health policy, and underscore the need for longitudinal analyses of these behaviours.

- The study found that current tobacco users are more likely to search online for e-cigarette information, perhaps indicating that they perceive the products as smoking cessation aids.

Acknowledgements The authors would like to thank Eman Aly and Yawen Liu for their excellent research assistance. 
Contributors SLE, LV, JH and GS together designed the study; GfK Group collected data; JH and GS conducted data analysis; SLE, LV, JH and GS contributed to data interpretation; SLE, LV and JH wrote the first draft and revised the draft; the final version of the paper has been reviewed and approved by all four coauthors.

Funding This project was funded by a National Cancer Institute-funded grant (grant no. 5U01CA154254), titled 'Tobacco Control in a Rapidly Changing Media Environment' (principal investigator: SLE). The National Cancer Institute did not play any role in study design; in the collection, analysis and interpretation of data; in the writing of the report and in the decision to submit the article for publication. The opinions expressed here are those of the authors and do not necessarily reflect those of the sponsors.

\section{Competing interests None.}

Ethics approval This study was cleared for ethics by Research Ethics Boards or International Review Boards at the University of Illinois at Chicago (US).

Provenance and peer review Not commissioned; externally peer reviewed.

Open Access This is an Open Access article distributed in accordance with the Creative Commons Attribution Non Commercial (CC BY-NC 3.0) license, which permits others to distribute, remix, adapt, build upon this work non-commercially, and license their derivative works on different terms, provided the original work is properly cited and the use is non-commercial. See: http://creativecommons.org/ licenses/by-nc/3.0

\section{REFERENCES}

1 Yamin CK, Bitton A, Bates DW. E-cigarettes: a rapidly growing Internet phenomenon. Ann Intern Med 2010;153:607-9.

2 Etter JF. Electronic cigarettes: a survey of users. BMC Public Health 2010;10:231.

3 Kuehn BM. FDA: electronic cigarettes may be risky. JAMA 2009;302:937.

4 Pauly J, Li Q, Barry MB. Tobacco-free electronic cigarettes and cigars deliver nicotine and generate concern. Tob Control 2007;16:357

5 Elliott S. E-cigarette makers' ads echo tobacco's heyday. The New York Times [Internet]. 29 August 2013. http://www.nytimes.com/2013/08/30/business/media/ e-cigarette-makers-ads-echo-tobaccos-heyday.html

6 Associated Press. Old tobacco playbook gets new use by e-cigarettes. The Patriot-News_PennLive.com [Internet]. 3 August 2013. http://www.pennlive.com/ midstate/index.ssf/2013/08/electronic_cigarettes_marketin.html

7 Noel JK, Rees VW, Connolly GN. Electronic cigarettes: a new "tobacco" industry? Tob Control 2010:20:81.

8 Pearson JL, Richardson A, Niaura RS, et al. E-cigarette awareness, use, and harm perceptions in US adults. Am J Public Health 2012;102:1758-66.
9 Adkison SE, O'Connor RJ, Bansal-Travers $\mathrm{M}$, et al. Electronic nicotine delivery systems: International Tobacco Control Four-country Survey. Am J Prev Med 2013;44:207-15

10 Centers for Disease Control and Prevention. Electronic cigarette use among middle and high school students-United States, 2011-2012. MMWR Morb Mortal Wkly Rep 2013;62:729.

11 Health Media Collaboratory. Prevalence, Awareness, Risk Perceptions, and Motivations for use of E-Cigarettes Among U.S. Adults. Chicago, IL: Health Media Collaboratory, University of Illinois Chicago, 2014. (White paper.)

12 The GfK Group. Knowledge panel design summary. Palo Alto, CA: The GfK Group, 2013.

13 U.S. Department of Health \& Human Services. The health consequences of smoking - 50 years of progress: a report of the Surgeon General [Internet]. Atlanta, GA: U.S. Department of Health and Human Services, Centers for Disease Control and Prevention, National Center for Chronic Disease Prevention and Health Promotion, Office on Smoking and Health, 2014. http://www.surgeongeneral.gov/ library/reports/50-years-of-progress/index.html

14 King BA, Alam S, Promoff G, et al. Awareness and ever use of electronic cigarettes among U.S. adults, 2010-2011. Nicotine Tob Res 2013;15:1623-27.

15 Regan AK, Promoff G, Dube SR, et al. Electronic nicotine delivery systems: adult use and awareness of the "e-cigarette" in the USA. Tob Control 2011;22:19-23.

16 Saffer $\mathrm{H}$, Chaloupka $\mathrm{F}$. The effect of tobacco advertising bans on tobacco consumption. J Health Econ 2000;19:1117-37.

17 Jones WJ, Silvestri GA. The Master Settlement Agreement and its impact on tobacco use 10 years later: lessons for physicians about health policy making. Chest 2010;137:692-700

18 Durbin RJ, Waxman HA, Harkin T, et al. Gateway to addiction? A survey of popular electronic cigarette manufacturers and targeted marketing to youth [Internet]. Washington DC: U.S. Congress, 2014. http://www.durbin.senate.gov/publidindex.cfm/ files/serve/?File_id=81d14ff7-f2f6-4856-af9d-c20c0b138f8f (accessed 14 Apr 2014).

19 Sebastian M, McDermott J. Is big tobacco back as a big advertiser? Ad Age Media News [Internet] 2013. http://adage.com/article/media/big-tobacco-spending-adse-cigarettes/241993/ (accessed 10 Jun 2013)

20 Fox S, Duggan M. Peer-to-peer health care [Internet]. Pew Research Center's Internet \& American Life Project, 2013. http://www.pewinternet.org/2013/01/15/ peer-to-peer-health-care/ (accessed 24 Feb 2014).

21 Paek H-J, Kim S, Hove T, et al. Reduced harm or another gateway to smoking? Source, message, and information characteristics of e-cigarette videos on YouTube. J Health Commun 2014;19:545-60.

22 Huang J, Szczypka G, Kornfield R, et al. A cross-sectional examination of marketing and promotion of electronic cigarettes on Twitter. Tob Control 2014;23:iii26-30.

23 Kornfield R, Huang J, Vera L, et al. Industry watch: rapidly increasing promotional expenditures for e-cigarettes. Tob Control 2014. In press. 